\title{
Persistent Trigeminal Artery with a Cerebellar Branch and Trigeminal-Cavernous Fistula from Ruptured Aneurysm: Transarterial Coil Embolization
}

\author{
Byung Moon Kim, MD', Dong Ik Kim, MD', Tai Hyung Kwon, MD¹
}

We report a case of persistent trigeminal artery (PTA) with a cerebellar branch supplying the posterior inferior cerebellar arterial territory, combined with a trigeminal-cavernous fistula resulting from rupture of an aneurysm at proximal trunk of the PTA. The fistula was successfully treated by transarterial coil embolization with preservation of PTA.

Key Words : Persistent trigeminal artery; Arterio-venous fistula; Transarterial coil embolization

Persistent trigeminal artery (PTA) is the most common internal carotid artery (ICA) -basilar artery anastomosis with an incidence between $0.1 \%$ and $0.3 \%$ (1). Anomalous cerebellar artery originating from the PTA has rarely been reported (2, 3). Rarely when an aneurysm is combined and ruptures into the cavernous sinus, spontaneous trigeminal-cavernous fistula can develop, which is usually treated by transarterial detachable balloon embolization or transvenous coil embolization (4-7).

We report a rare case of PTA with an arterial branch supplying the inferior cerebellum, combined with a trigeminal-cavernous fistula, which was successfully treated solely by transarterial coil embolization.

'Department of Radiology, Severance Hospital, Yonsei University College of Medicine, Seoul, Korea

Received October 17, 2009;

accepted after revision November 29, 2009.

Correspondence to: Byung Moon Kim, MD, Department of Radiology, Severance Hospital, Yonsei University College of Medicine, 250 Seongsanno, Seodaemun-gu, Seoul 120-752, Korea.

Tel. 82-2-2228-2399 Fax. 82-2-393-3035

E-mail: bmoon21@hanmail.net

Neurointervention 2010;5:32-35

\section{CASE REPORT}

A 42-year-old, previously healthy woman presented with sudden onset of severe headache, exophthalmos, and diplopia. The patient denied any history of head trauma. Carotid-cavernous fistula was suspected clinically and cerebral angiography was performed. Left internal carotid angiography in Town's projection and lateral projection showed the typical appearance of a carotid-cavernous fistula. However, oblique lateral projection disclosed the fistula between the proximal trunk of a PTA and inferior cavernous sinus (Fig. 1A). Left vertebral angiography also revealed the trigeminal-cavernous fistula, along with a prominent inferior cerebellar branch at its cisternal portion.

After careful review of multiple projections of left internal carotid angiography, transarterial coil embolization of the fistula was attempted. A 6-F guiding catheter (Enboy; Cordis, Miami, USA) was positioned at cervical segment of the left internal carotid artery. A microcatheter (Renegade; Boston Scientific, Watertown, USA) and a 0.014-inch guidewire (Synchro; Boston Scientific) were navigated through the PTA, the fistula hole, and then to the left cavernous sinus. After forming the frame of the first 
coil near the fistula with a $5 \mathrm{~mm} \times 15 \mathrm{~cm}$ detachable platinum coil (Boston Scientific), ten fibered platinum coils (Boston Scientific) were further inserted into cavernous sinus. An angiogram performed with subtotal occlusion of the fistula disclosed aneurysmlike sac at PTA side of the fistula (Fig. 1B). Postembolization angiography of left internal carotid artery and left vertebral artery revealed complete occlusion of the fistula and well preserved PTA, including the inferior cerebellar branch (Fig. 1C, D). The symptoms of headache, dizziness, and diplopia subsided gradually after embolization, and the patient was symptom-free 6months after embolization. MR angiograms also revealed the well-preserved PTA and the inferior cerebellar artery without evidence of the fistula recurrence.

\section{DISCUSSION}

A few cases of carotid-cavernous fistula associated PTA has been reported. One possible explanation for the spontaneous trigeminal-carotid fistula is rupture of an aneurysm at origin or proximal trunk of the PTA. In our case, the fistula spontaneously developed and an

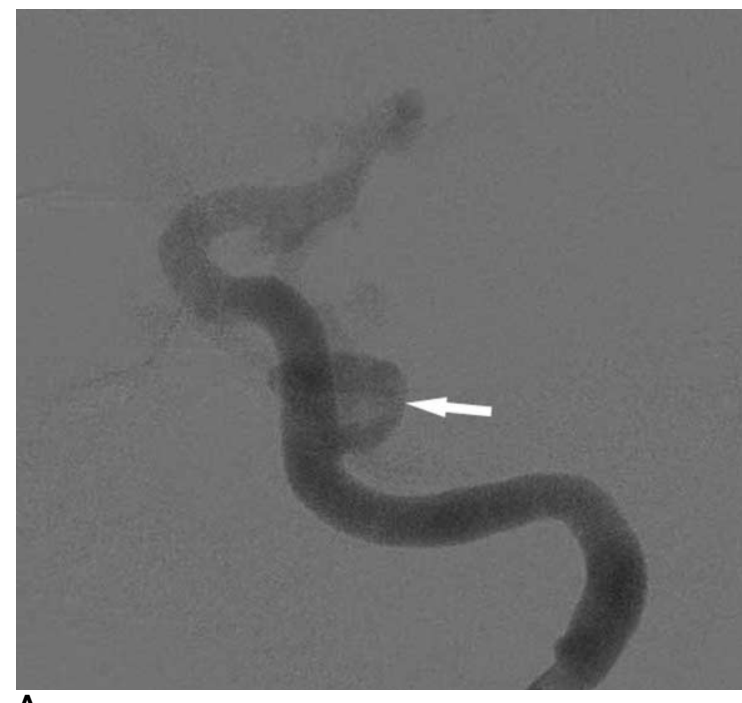

A
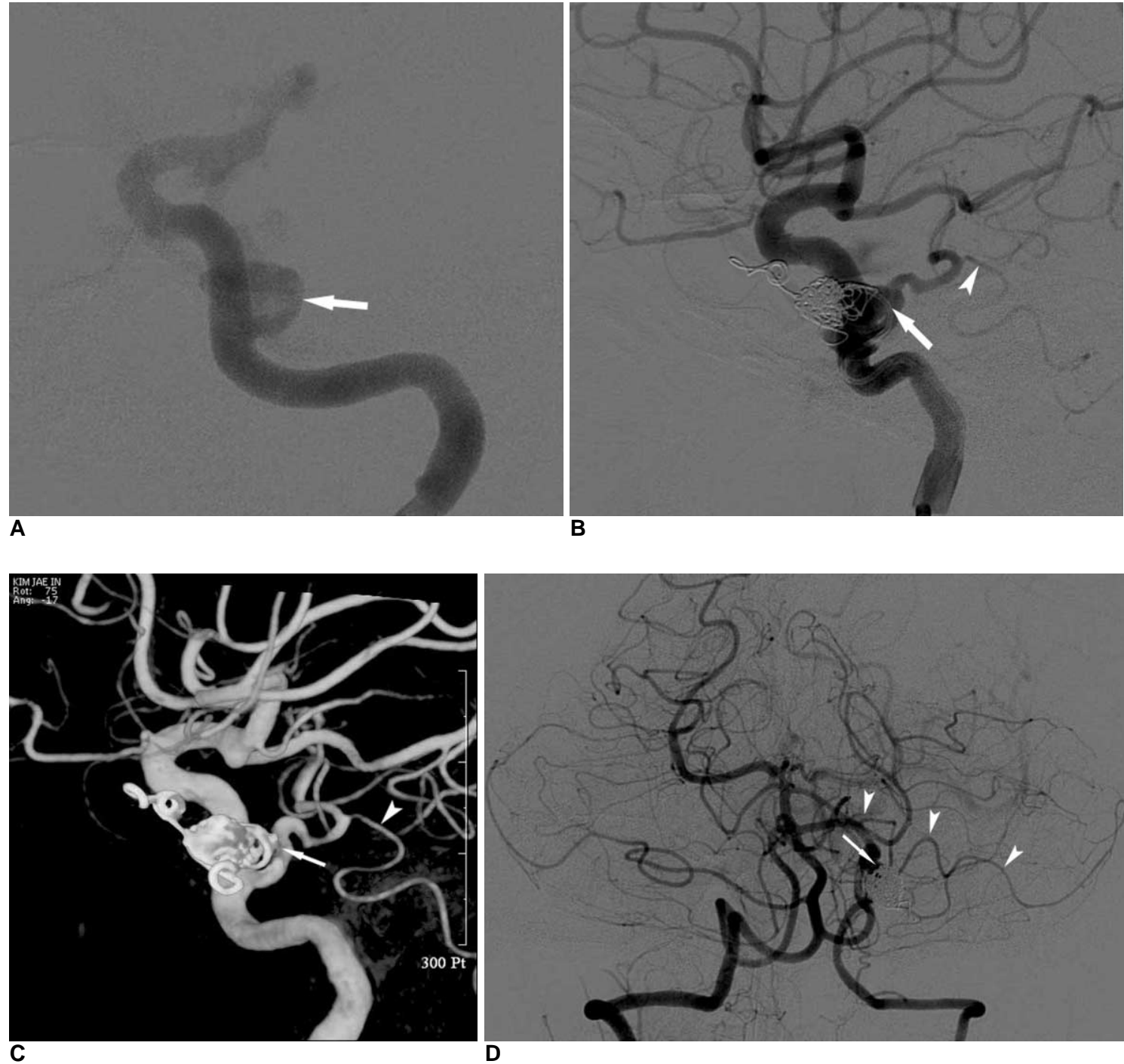

Fig. 1. Images of 42-year-old woman with persistent trigeminal artery and trigeminal-cavernous fistula.

A. Oblique view of left internal carotid artery reveals a fistula hole (arrow) between the proximal trunk of the persistent trigeminal artery and the cavernous sinus.

B. An angiogram with subtotal occlusion of the fistula reveals aneurysm-like sac (arrow) at the proximal trunk of the persistent trigeminal artery. A prominent inferior cerebellar artery (arrowhead) branches off from the cisternal portion of persistent trigeminal artery.

C, D. After completion of embolization with coils, 3-D reconstruction images of left internal carotid angiogram and left vertebral angiogram reveals complete occlusion of the fistula (arrow) and well preserved persistent trigeminal artery and the inferior cerebellar artery (arrowhead), which supplies the territory of posterior inferior cerebellar artery in the cerebellum. 
aneurysm-like sac was observed at the fistula point of the proximal trunk of PTA. The angiographic and clinical findings strongly suggest that the fistula occurred due to rupture of an aneurysm at the proximal trunk. Aneurysms associated with PTA were reported to arise at its origin from the internal carotid artery, cavernous portion, cisternal portion, or basilar artery junction. Rupture of an aneurysm at its origin or the cavernous trunk causes carotid-cavernous fistula, while rupture of an aneurysm at the cisternal trunk or basilar junction results in subarachnoid hemorrhage. The pathogenesis of the aneurysm of the PTA trunk is not well known. One suggests congenital defect of the middle layer of the PTA combined with hemodynamic stress induced by its anatomic location between two major arterial systems. An alternative explanation is that the aneurysm arises from the origin of the branches of the PTA. Anatomically, PTA can be classified into two variants according to its relationship with the abducens nerve; the lateral or inferior variant, and the medial or superior variant $(8-10)$. The medial variant of the PTA originates from superomedial portion of cavernous ICA, passes through the dorsum sella, courses medial to the abducens nerve, and then enters the anterior aspect of the basilar artery. The lateral variant of the PTA originates from inferolateral portion of cavernous ICA, passes lateral to the dorsum sella, courses lateral to the abducens nerve, and then enters the lateral aspect of the basilar artery. The lateral or inferior variant of the PTA can give the meningohypophysial trunk, the artery of inferior cavernous sinus in cavernous portion, and perforating branches into the trigeminal nerve root and pons $(8,9)$. Angiographically, our case of PTA is consistent with the lateral variant, and the aneurysm may have occurred at the origin of its small branches of the proximal trunk.

A prominent inferior cerebellar branch was seen to originate from the cisternal segment of the PTA, supplying the territory of left posterior inferior cerebellar artery. The anomalous cerebellar branch arising from the PTA has been rarely reported $(2,3)$. Our case of the PTA, along with previous reports $(2,3)$, strongly suggests that the cerebellar artery arising from ICA is a variant of the lateral variation of PTA.

Several cases of endovascular treatment of the trigeminal-cavernous fistulas have been reported, using transarterial balloon embolization with sacrifice of the PTA and/or the ICA, or transvenous coil embolization $(4,6,8)$. Bernstein et al. reported a case of transvenous coil embolization of a trigeminal-cavernous fistula followed by transarterial coil embolization for occlusion of residual flow through the PTA from basilar route (6). In our case, we decided the PTA should be preserved, because PTA gives off a prominent inferior cerebellar artery and because small branches to the pons and the trigeminal nerve root may branch from the PTA. In addition, while left inferior petrosal sinus was poorly visualized, the fistula hole was clearly visualized on angiography. Therefore, we decided on the transarterial route than the transvenous route for endovascular treatment, and easily treated the fistula with preservation of the PTA.

Lateral variants of the PTA can have cerebellar branches as well as perforating branches to the pons and trigeminal nerve root. We report a case of PTA with a prominent inferior cerebellar artery originating from the PTA, which also is a lateral variant, combined with trigeminal-cavernous fistula. Also, transarterial coil embolization of the trigeminal-cavernous fistula may be a feasible, time saving and safe technique for treatment of the trigeminal-cavernous fistula.

\section{References}

1. George AE, Lin JP, Morantz RA. Intracranial aneurysm on a persistent primitive trigeminal artery. J Neurosurg 1971;35:601-4

2. Parkinson D, Shields CB. Persistent trigeminal artery: its relationship to the normal branches of the cavernous carotid. J Neurosurg 1974:40:244-8

3. Uchino A, Sawada A, Takase Y, Kudo S, Koizumi T. Moyamoya disease associated with an anterior inferior cerebellar artery arising from a persistent trigeminal artery. Eur Radiol 2002;12: S14-S17

4. Debrun GM, Davis KR, Nauta HJ, Heros RE, Ahn HS. Treatment of carotid cavernous fistula or cavernous aneurysms associated with a persistent trigeminal artery: report of three cases. AJNR Am J Neuroradiol 1988;9:749-55

5. Guglielmi G, Viñuela F, Dion J, Duckwiler G, Cantore G, Delfini R. Persistent primitive trigeminal artery-cavernous sinus fistulas: report of two cases. Neurosurgery 1990;27:805-8

6. Bernstein K, Teitelbaum GP, Herman B, Giannotta SL. Coil embolization of a trigeminal-cavernous fistula. AJNR Am J Neuroradiol 1998;19:1953-4

7. Oka Y, Sadamoto K, Tagawa M, Kumon Y, Sakaki S, Fujita M. Transvenous embolization of carotid-cavernous sinus fistula associated with a primitive trigeminal artery. Neurol Med Chir (Tokyo) 2000;40:61-4

8. Suttner N, Mura J, Tedeschi H, Ferreira MA, Wen HT, de Oliveira E, et al. Persistent trigeminal artery: a unique anatomic specimen analysis and therapeutic implications. Neurosurgery 2000;47: 428-33

9. Ohshiro S, Inoue T, Hamada Y, Matsuno H. Branches of the persistent primitive trigeminal artery-an autopsy case. Neurosurgery 1993;32:144-8

10. Salas E, Ziyal IM, Sekhar LN, Wright DC. Persistent trigeminal artery: an anatomic study. Neurosurgery 1998;43:557-62 


\section{지속성 원시 삼차신경동맥 동맥류의 파열에 의한 삼차신경동맥-해면정맥동루의 혈관내치료}

${ }^{1}$ 연세대학교 의과대학 세브란스병원 영상의학과

$$
\text { 김병문 }
$$

저자들은 후하소뇌동맥영역을 공급하는 가지혈관을 가진 지속성 원시 삼차신경동맥에 생긴 동맥류의 파열에 의 한 삼차신경동맥-해면정맥동루의 증례를 보고한다. 이 동정맥루는 경동맥 코일 색전술 (transarterial coil embolization)로 성공적으로 치료하였다.

Key Words : Persistent trigeminal artery; Arterio-venous fistula; Transarterial coil embolization 